\title{
On the nature of arguments in event nominals
}

\author{
Irina Burukina*
}

\begin{abstract}
The present paper examines deverbal event nouns in Kaqchikel (Mayan) that consist of both nominal and verbal projections. Contrary to the recent proposal made by Imanishi (2020), who argues that nominalized verbs in Kaqchikel obligatorily lack an external argument projection, we demonstrate that intransitive unergative predicates maintain their external arguments under nominalization. We further propose that event $-i k$ nouns in Kaqchikel are derived via predicative control with the verbal part being predicated of the possessor DP introduced in Spec,nP (in the spirit of Landau 2015). Additional support for this comes from the behavior of antipassive predicates under nominalization, which preserve the internal argument instead of the external one.
\end{abstract}

Keywords. nominalization; mixed categories; argument structure; unergative; predicative control; Mayan

1. Introduction. One of the prevalent approaches to event nominalization is the mixed projection approach, whereby a deverbal noun consists of a verbal extended projection that hosts the arguments and a nominal projection that determines the grammatical category of the word; see, among others, Grimshaw (1990), Bresnan (1997), Marantz (1997), Borsley \& Kornfilt (2000), and Alexiadou (2001). The present paper examines event -ik nominalization in the variety of Kaqchikel (Mayan; ergative, VOS/SVO) spoken in Patzún, Guatemala in an attempt to answer the following two questions: (1) What argument positions are available within the verbal part? and (2) What is the status of the arguments?

Regarding the first question, in a recent paper Imanishi (2020) has proposed the following Restriction on Nominalization: (in Kaqchikel) all nominalized verbs must lack a syntactically projected external argument. ${ }^{1}$ The restriction is a parameter: while it is active in Kaqchikel it does not apply to other Mayan languages, such as Chol and Q'anjob'al. In this paper we present novel data from Kaqchikel not discussed by Imanishi to demonstrate that external arguments can survive nominalization. In particular, we will show that an unergative predicate can be nominalized using the $-i k$ suffix and the Agent argument is preserved in the derived noun.

Considering the second question regarding the status of the argument, at least the following two options are available. On the one hand, it has been proposed that lexical DPs are merged externally within the verbal extended projection; see Borsley \& Kornfilt (2000), Alexiadou (2001), and, on Mayan, Imanishi (2020). On the other hand, Yoon (1996), van Hout \& Roeper (1998), Baker (2005), and, for Mayan languages, Coon (2010) argue that the argument

\footnotetext{
* I am very grateful to my consultants in Patzún, Guatemala, especially to Irma Yolanda Raquec Teleguario, Filiberto Patal Majzul, Gloria Imelda Ixim, Gloria Esmeralda Canú Chirix, and Celsa Teleguario. I would like to thank Maria Polinsky, Marcel den Dikken, Rodrigo Ranero, Pedro Mateo Pedro, and the reviewers and the audience at LSA95. A special thank you to Alexandra Kubatieva for the help with the research and the LSA presentation. All mistakes are mine. The fieldwork for this project was supported by Jacobs Research Funds grants (2018 - 2020); the research is funded by the Hungarian National Research, Development and Innovation Office under the grant NKFI 129921. Author: Irina Burukina, Hungarian Research Centre for Linguistics \& Eötvös Loránd University (irina.burukina@btk.elte.hu).

${ }^{1}$ The Restriction on Nominalization parallels the unaccusative generalization put forward earlier by Alexiadou (2001) based on data from several Indo-European languages.
} 
positions are occupied by PROs bound by higher DPs in a nominal projection. ${ }^{2}$ Having examined event nominals in Patzún Kaqchikel, we propose that -ik nominalization involves predicative control established between the verbal part (the predicate) and the $\mathrm{DP}_{\text {poss }}$ in the nominal part (the subject), in the spirit of Williams (1980) and Landau (2015).

Thus, the Kaqchikel data contribute to the discussion of deverbal nominalizations and mixed categories and expand the range of constructions examined in the work on control and raising/ECM, which often limits itself to verbal predicates and the clausal domain. As we will further show, additional support for the proposed analysis comes from the previously undescribed behavior of antipassive under nominalization: in clausal antipassive only the external argument survives but antipassive in nominals instead promotes the internal argument. While this phenomenon is accounted for under a PRO-approach, it poses a serious problem for a lexical-DP analysis.

The paper proceeds as follows. Section 2 discusses the relevant properties of event $-i k$ nouns. Section 3 addresses the question about the size of the verbal extended projection in mixed nominals and the presence of an external argument position. Section 4 focuses on the status of the arguments in -ik nominals and presents a novel control analysis for deverbal nominalization. Section 5 provides additional support for the analysis and Section 6 concludes the paper.

2. Deverbal -ik nominalization: General properties. Event -ik nominalization in Kaqchikel applies to inherently intransitive and detransitivized predicates. Consider, for instance, examples in (1), where the transitive verb tijoj 'teach' must first be passivized to become suitable for nominalization. ${ }^{3}$

(1) Nominalizing a passivized predicate
a. Röj $x-\varnothing$-qa-tijo-j ri ala'.
we CMP-B3S-A1P-teach-TV DET boy
'We taught the boy.'
b. Ri ala' $x-\varnothing$-tijo-x.
DET boy CMP-B3s-teach-PAS
'The boy was taught.'
c. Röj x-Ø-qa-chäp
(ri) (*qa-)ru-tijo-x-ik
(*öj) ri ala'.
we CMP-B3S-A1P-begin DET A1P-A3S-teach-PAS-NMZ we DET boy
'We began teaching the boy.'
Literally: 'We initiated the boy's teaching.'

As evident in the example above, when a passive predicate is nominalized the external argument must be absent, just as in clausal passive, and the internal argument is matched by an ergative/possessive marker. In Kaqchikel, similarly to other Mayan languages, ergative and possessive (genitive) share the paradigm. The list of agreement markers is given in (2); fol-

\footnotetext{
${ }^{2}$ Most of the authors listed here do not provide sufficient argumentation for either of the approaches. The exception known to us is Baker (2005), who justifies the PRO analysis for English gerunds by noticing that they are incompatible with true expletives and that idiom chunks are degraded, similarly to those in ordinary control constructions (??All hell's having broken loose was very upsetting).

${ }^{3}$ Glossing abbreviations: $\mathrm{A}=$ Set $\mathrm{A}$ (ergative/possessive), $\mathrm{AP}=$ antipassive, $\mathrm{B}=$ Set $\mathrm{B}$ (absolutive), $\mathrm{CAUS}=$ causative, $\mathrm{CL}=$ classifier, $\mathrm{CMP}=$ completive, $\mathrm{DET}=$ determiner, $\mathrm{FOC}=$ focus, $\mathrm{ICMP}=$ incompletive, $\mathrm{NMZ}=$ nominalizer, $\mathrm{P}=$ plural, $\mathrm{PAS}=$ passive, $\mathrm{PROG}=$ progressive, $\mathrm{RN}=$ relational noun, $\mathrm{S}=$ singular, $\mathrm{TV}=$ transitive .
} 
lowing the Mayanist tradition, throughout the paper we gloss ergative/possessive as (Set) A and absolutive as (Set) B.

Agreement markers, clitics, and pronouns

\begin{tabular}{|l|cc|c|c|}
\hline & Set A before C & Set A before V & Set B & Free pronouns \\
\hline 1SG & $\mathrm{nu} / \mathrm{in} / \mathrm{n}$ & $\mathrm{w} / \mathrm{inw} / \mathrm{nw}$ & in & rïn \\
2SG & $\mathrm{a}$ & $\mathrm{aw}$ & at & rat \\
3SG & $\mathrm{ru} / \mathrm{u}$ & $\mathrm{r}$ & $\varnothing$ & rija' \\
1PL & $\mathrm{qa}$ & $\mathrm{q}$ & oj & röj \\
2PL & $\mathrm{i}$ & $\mathrm{iw}$ & ix & rïx \\
3PL & $\mathrm{ki}$ & $\mathrm{k}$ & $\mathrm{e}$ & rije' \\
\hline
\end{tabular}

Similarly to mixed categories in other languages (cf. for example, English ACC-ing gerunds) event $-i k$ nouns exhibit both nominal and verbal properties. Typically for nouns, they allow determiners and prohibit (in)completive Tense-Aspect marking, which is obligatory for finite verbs (3).
a. $\quad \mathrm{N}-\varnothing$-inw-ajo'
ri $\quad(* x / * n-) r u-k a n-u x-i k$
ri llave.
ICMP-B3S-A1S-want DET CMP/ICMP-A3S-search-PAS-NMZ DET key
'I want (someone) to look for the key.'
b. ri llave / (*ri) x-oj-oq'. / *oj-oq'
DET key DET CMP-B 1P-cry B1P-cry
'the key' / 'We cried.' / 'We cried.'

On the other hand, similarly to verbs, -ik nominals can contain Voice morphology (recall the passive examples above) and are compatible with exclusively verbal adjuncts, such as aninäq 'quickly' (4).
a. a-kan-ux-ik aninäq
A2s-search-PAS-NMZ quickly
'quickly searching for you'
b. *aninäq tzij /*samaj aninäq
quickly word work(noun) quickly
Intended: 'quick word' / 'quick work'
c. Rat $x$-at-kan-ux aninäq.
you CMP-B2s-search-PAS quickly
'You were quickly searched for.'

Taking this dual behavior into account, we conclude that -ik nominals consist of a core verbal part dominated by several nominal projections that regulate the distribution of the item in a clause; see also an extensive discussion of English gerunds as mixed categories in Bresnan 1997, Borsley \& Kornfilt 2000, Alexiadou 2001, and Panagiotidis \& Grohmann 2009, to name a few.

We further follow the existing literature on nominalization in Mayan and assume that the verbal extended projection of -ik nominals is a $\mathrm{vP} /$ VoiceP and that nominal projections include at least an $\mathrm{nP}$, where a possessor can be introduced, and a DP, which accommodates a determiner (Coon \& Carolan 2010, Imanishi \& Mateo Pedro 2013, Imanishi 2020, i.a.). A preliminary structure for even $-i k$ nouns is given in (5), to be revised later in the paper. 
Preliminary structure of event $-i k$ nouns

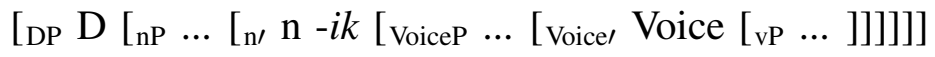

Within the verbal part of an $-i k$ nominal there is no source for case and ergative/possessive is assigned by the D head to a possessor in Spec,nP. Kaqchikel is a so-called 'HIGH-ABS' language where the absolutive case is uniformly assigned by Infl, while ergative is assigned by transitive Voice; the structure of a finite clause is shown in (6), where the internal argument undergoes raising to Spec,VoiceP to be probed by Infl (Coon et al. 2014).

(6) Structure of finite clauses

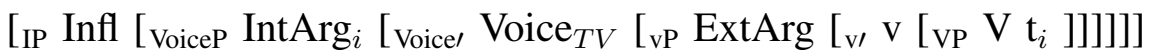

\section{External arguments under nominalization.}

3.1. IMANISHI's (2020) RESTRICTION ON NOMINALIZATION. In a recent paper Imanishi (2020) discusses $-i k$ nominals in Kaqchikel, focusing mostly on nominalized passive predicates. Considering examples such as the one in (7-a), where the possessive morpheme on the derived noun must cross-reference the internal argument, Imanishi further compares them to instances of inherently intransitive event nominals (7-b), where the possessive morpheme is absent.

(7) a. Ri ru-tzaq-ik ri a Juan ütz.

DET A3S-fall-NMZ DET CL Juan good

'Juan's falling is good.' [Imanishi 2020: (69)]

b. Rat $x$ - $\varnothing$-a-chäp atin-ik.

you CMP-B3S-A2S-begin bathe-NMZ

'You began to bathe.' [ibid.: (75)]

To account for the apparent absence of a Set A marker matching the external argument in these examples, Imanishi introduces the following Restriction on Nominalization (8), which falls in line with Alexiadou's (2001) proposal that in many European languages only unaccusative verbs can be nominalized. The restriction is a parameter that marks the difference between Kaqchikel and other Mayan languages.

(8) Restriction on Nominalization (Imanishi 2020)

In Kaqchikel, the nominalized verb must lack a syntactically projected external argument.

However, the Restriction on Nominalization turns out to be too severe and does not match the actual data. A particular context in which - $i k$ nouns appear that becomes crucial for the present discussion and that is overlooked in Imanishi's work is the complement position of desiderative verbs, such as ajo' 'want, like' and rayij 'desire'. The data are examined in the next subsection.

3.2. Against the Restriction. Support for the Restriction on Nominalization comes primarily from contrasting such examples as (7-b) and (9). The sentence in (7-b) involves a nominalized presumably unergative predicate; there is no Set A marker cross-referencing the external argument. The example in (9) involves a nominalized unaccusative predicate; the internal argument is encoded via a Set A prefix. 
(9) Ri ru-tzaq-ik ri a Juan ütz.

DET A3S-fall-NMZ DET CL Juan good

'Juan's falling is good.' [Imanishi 2020: (69)]

Note, however, that most of the examples considered by Imanishi (2020) contain an -ik nominal embedded under the verbs ajin PROG and chäp 'begin', which naturally enforce coreference between the matrix subject and the understood Agent of the nominalized predicate. In such cases many speakers of the Patzún variety of Kaqchikel report that using a Set A prefix in the examples similar to (7-b) is preferable although optional (10). One possible explanation for the optionality is to assume that the speakers choose between the two strategies to establish coreference between the main and the embedded Agents: non-obligatory control of $\mathrm{PRO} / \mathrm{PRO}_{A R B}$ (7-b) and binding of an overt pronoun (10).

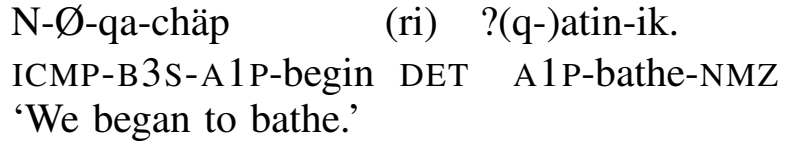

Other verbs that embed $-i k$ nominals include ajo' 'want, like' and rayij 'desire'. Unlike ajin PROG and chäp 'begin' they often describe situations involving distinct participants: the one who wants something and the one who would perform in the desired situation are not the same person. Importantly, when these verbs embed a nominalized inherently intransitive predicate the latter is accompanied by a Set A marker that cross-references the embedded argument (11).

(11) Nominalizing an unergative predicate
a. N-Ø-inw-ajo' (ri) k-atin-ik ri ak'wala' aninäq.
ICMP-B3S-A1S-want DET A3P-bathe-NMZ DET children quickly
'I want the children to bathe quickly.'
b. N-Ø-aw-ajo' (ri) nu-b'iyin-ik aninäq.
ICMP-B3S-A2s-want DET A1S-walk.VB-NMZ quickly
'You want me to walk quickly.'
c. N-Ø-inw-ajo' (ri) ru-tzopin-ik ri xta Maria aninäq.
ICMP-B3S-A1 S-want DET A3S-jump.VB-NMZ DET CL Maria quickly
'I want Maria to jump quickly.'

In (11), all -ik nouns are derived from intransitive predicates; they are accompanied by the adverb aninäq, which indicate that they are indeed event and not result nominals. Under the assumption that the verbs atin, b'iyin, and tzopin are unergative, in parallel to their translation equivalents in English, the data in (11) prove that external arguments can survive nominalization, contrary to the Restriction on Nominalization.

3.3. Unergative vs. unaccusative: Optional agreement. A potential counterargument would be to propose that the intransitive verbs in (11) are all unaccusative. In what follows we will present the results for the agreement test that show that the sole argument of the intransitive predicates nominalized in (11) patterns with transitive subjects, while the sole argument of other intransitive verbs, such as $t z a q$ 'fall', patterns with transitive objects.

The test was originally designed by Levin et al. (2021) for Santiago Tz'utujil. The empirical observation behind this test is that, while all plural subjects of transitive verbs must be matched by a plural marker, third person plural objects and arguments of such verbs as tzaq 
'fall' are only optionally doubled by a plural absolutive clitic. The optionality is conditioned syntactically: agreement is obligatory when the controller is an external argument and it is optional when the controller is an internal argument. A similar pattern is observed in Kaqchikel: plural third person objects do not have to be cross-referenced by ABS (12-a), while agreement with subjects of transitive verbs is obligatory (12-b). Although Levin et al. (2021) mention that in Tz'utujil the optionality of agreement is attested only for inanimate arguments, our Kaqchikel consultants allow optional agreement for [-Human] controllers, both inanimate and animate.
a. Röj x-e/Ø-qa-q'ete-j ri oxi' tz'i'.
we CMP-B3P/Ø-A1P-hug-TV DET three dog
'We hugged the three dogs.'
b. Ri oxi' tz'i' $x-\varnothing-k i /{ }^{*} \varnothing$-tz'ët rija'.
DET three dog CMP-B3S-A3P/Ø-see s/he
'Three dogs saw him/her.'

Some intransitive verbs, including tzaq 'fall', do not have to encode their sole argument via ABS. In contrast, such agentive verbs as tzopin 'jump', b'iyin 'walk', and atin 'bathe' prohibit the agreement mismatch; compare (13-a) to (13-b) and (13-c).
a. $\quad$ Ri ox’i tz'i’ x-e/Ø-tzaq.
DET three dog CMP-B3P/Ø-fall
'The three dogs fell.'
b. $\mathrm{Ri}$ oxi' tz'i' x-e/*Ø-tzopin.
DET three dog CMP-B3P/Ø-jump.VB
'The three dogs jumped.'
c. $\mathrm{Ri}$ oxi' syan $\mathrm{x}-\mathrm{e} /{ }^{*} \varnothing$-atin.
DET three cat CMP-B3P/Ø-bathe
'The three cats bathed.'

Thus, the argument of the predicates tzopin 'jump', b'iyin 'walk', and atin 'bathe' patterns with transitive subjects, i.e. external arguments, and not with transitive objects, i.e. internal arguments, which confirms the unergative status of these verbs and allows us to conclude that the examples in (11) posit a genuine problem for the Restriction on Nominalization. Event $-i k$ nouns can contain a syntactically projected external argument; a revised structure is given in (14), where either an internal argument or an external argument is present.

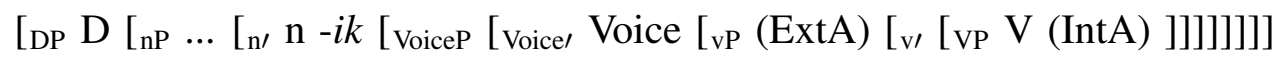

\section{Analysis: Predicative control.}

4.1. OutLine. The question remains of whether the argument position within the extended verbal projection of an -ik nominal is occupied by a lexical DP or PRO bound by the higher possessor. Imanishi (2020) tentatively adopts the former approach, although he does not provide additional support for it. In contrast, we follow Coon (2010), i.a., and argue that control is established within an event noun.

In particular, we argue that the verbal part of an -ik nominal contains a PRO variable merged in the argument position. PRO is controlled by a higher possessor merged in Spec,nP via predicative control, following Landau (2015) on clausal complementation: predication is 
established between the possessor (the controller), which serves as the subject, and the extended verbal projection, which plays the role of the predicate. The vP/VoiceP becomes predicative with the help of a syntactic operator (in the case under discussion, PRO) that undergoes internal merge to the specifier position at the edge of the phrase. This is schematized in (15) for passive and unaccusative nominals.

(15) Predicative control in passive and unaccusative nominals
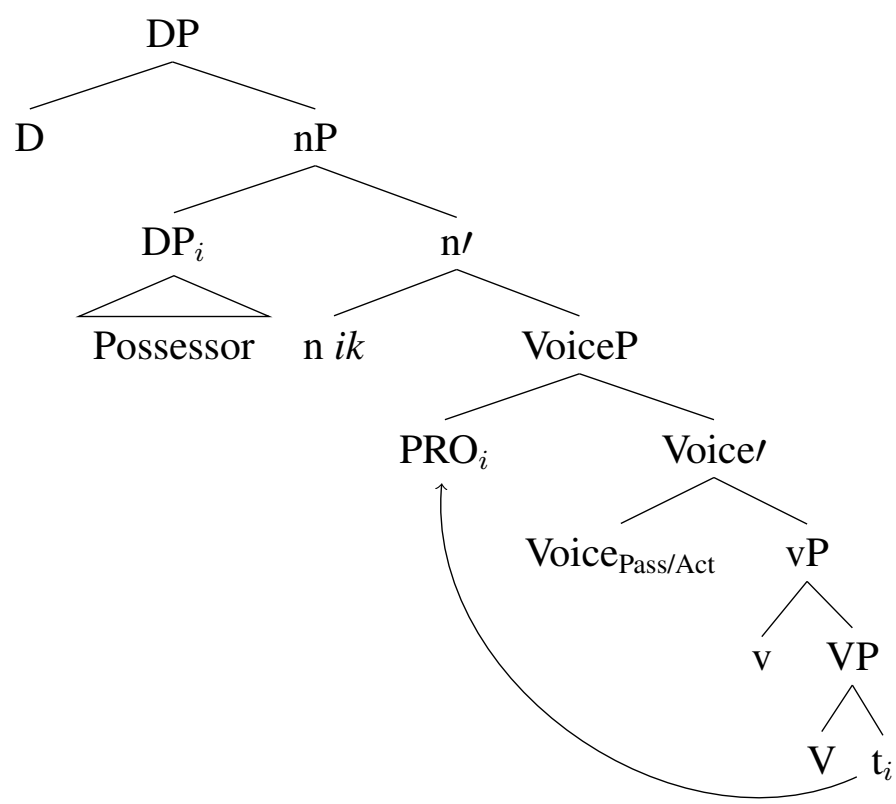

Nominalization of unergative verbs proceeds in a similar way (16), the difference being the starting position of PRO: Spec,vP instead of Comp,VP.

(16) Predicative control in unergative nominals

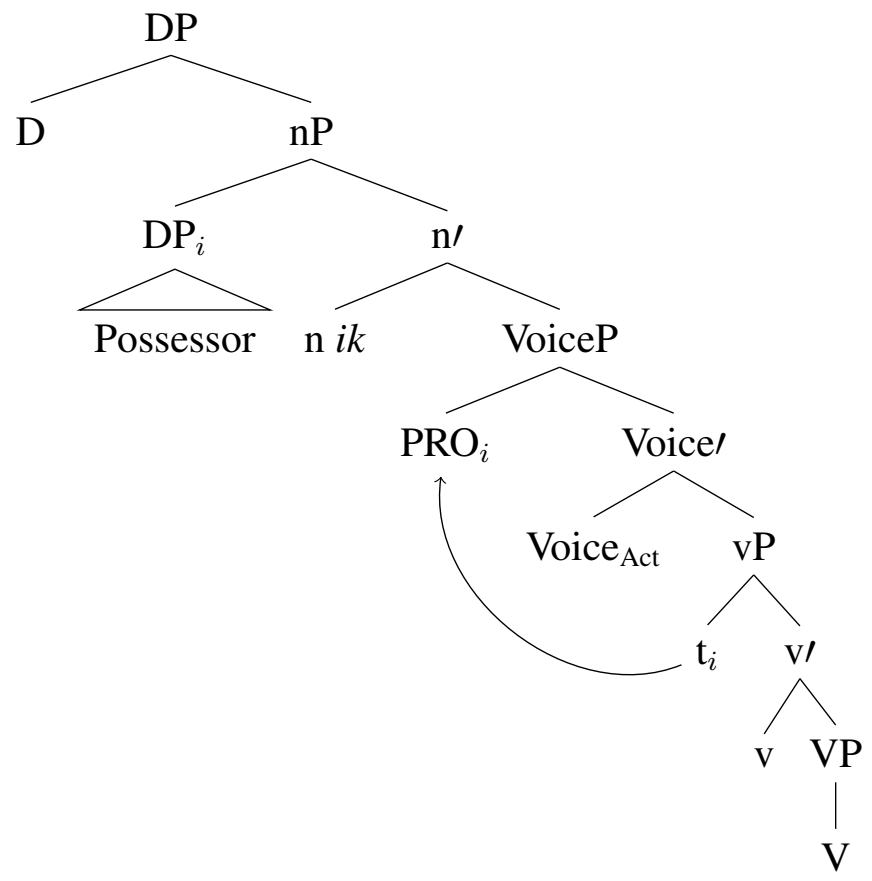


The proposed predicative control analysis correctly predicts that Kaqchikel -ik nouns fall into the exhaustive control category: because of the predication relation established between the two, partial coreference between the possessor DP and the implicit argument is unacceptable. For instance, the modifier junam 'together', which requires a semantically plural antecedent (17), is prohibited when the possessor of an -ik nominal is singular (18).
a. Junam $n-\emptyset$-qa-tijo-j
ri xta Maria.

together ICMP-B3S-A1P-teach-TV DET CL Maria

'We teach Maria together.'

Not available: 'We teach together Maria and someone.'

b. Junam y-e-n-tijo-j Juan y ri xta Maria.

together ICMP-B3P-A1S-teach-TV Juan and DET CL Maria

'I teach Juan and Maria together.'

Not available: 'I, together with someone, teach Juan and Maria.'
a. *ru-tijo-X-ik
ri Maria junam aninäq
A3S-teach-PAS-NMZ DET Maria together quickly
Intended: 'teaching of Maria and someone together'
b. ki-tijo-X-ik ri ak'wala' junam aninäq
A3P-teach-PAS-NMZ DET children together quickly
'teaching of the children together'

4.2. SUPPORT: PP POSSESSORS. Support for the control analysis comes from the behavior of possessors. Kaqchikel utilizes two types of possessors in nominal phrases: (i) DPs crossreferenced by a Set A marker on the possessum, and (ii) complex possessor phrases that are headed by the adposition-like relational noun $(i)$ chin. Crucially, both types of possessor phrases are compatible with event $-i k$ nominals (19)
a. N-Ø-inw-ajo'
ri ru-tijo-X-ik
ri xta Maria aninäq.
ICMP-B3S-A1S-want DET A3S-teach-PAS-NMZ DET CL Maria quickly
'I want Maria to be taught quickly.'
b. N-Ø-inw-ajo' ri tijo-X-ik r-chin ri xta Maria aninäq. ICMP-B3S-A1S-want DET teach-PAS-NMZ A3S-RN DET CL Maria quickly 'I want Maria to be taught quickly.' $(\mathrm{a}=\mathrm{b})$
c. N-Ø-inw-ajo' ri ru-tijo-X-ik r-chin ri xta Maria aninäq. ICMP-B3S-A1S-want DET A3S-teach-PAS-NMZ A3S-RN DET CL Maria quickly Only: 'I want someone to be taught quickly for Maria's benefit.'
(the ichin phrase can only be interpreted as a Beneficiary)

The $(i)$ chin phrase in (19-b) can only be analyzed as a higher possessor and not as an argument merged within the verbal part of a nominal, since demoted Agents of passivized verbs are headed by the relational noun uma (oma) but never by (i)chin (20).
a. $\quad \mathrm{Ri}$ ala' $\mathrm{x}-\varnothing$-tijo-x
DET boy CMP-B3S-teach-PAS A3S-RN DET CL Maria 'The boy was taught by Maria.'
r-uma ri xta Maria.
b. Ri ala' $\mathrm{x}-\varnothing$-tijo-x r-chin ri xta Maria. DET boy CMP-B3S-teach-PAS A3S-RN DET CL Maria Not available: 'The boy was taught by Maria.'


Only: 'The boy was taught for Maria's benefit.'

Thus, the only interpretation available for the (i)chin phrase in (19-b) is the possessive one. Under the assumption that sideward movement from Comp,VP into a complex $(i)$ chin phrase is not possible, a raising/ECM-type analysis is excluded. ${ }^{4}$ However, the predicative control analysis proposed in this paper (that is, a PRO-based approach to nominalization) accounts for all the relevant properties of event $-i k$ nominals, including the compatibility with PP possessors. As we will show in the next section, it also explains the previously undescribed behavior of Kaqchikel antipassive predicates under nominalization.

\section{Additional support: Nominalized antipassive.}

5.1. ANTIPASSIVE UNDER NOMINALIZATION PUZZLE. In this section we will present an additional piece of support for the proposed analysis in terms of predicative control. It comes from unusual and previously undescribed behavior of antipassive in event nominals that is hard to account for under a DP approach to deverbal nominalization.

In Kaqchikel finite clauses antipassive either completely removes the internal argument or demotes it to a bare (pseudo-incorporated) NP or an oblique (i)chin phrase; consequently, the verb is detransitivized and an ergative marker is prohibited. The morphological exponent of antipassive in the Patzún variety of Kaqchikel under discussion is $-V n{ }^{5}$

Antipassive in a finite clause

a. $\mathrm{Ri}$ alab'oni' $\mathrm{x}-\varnothing$-ki-tik

ri ixim.

DET men CMP-B3S-A3P-plant DET corn

'The men planted corn.'

b. Ri alab'oni' x-e-tik-on (ixim/r-chin ri ixim / *ri ixim).

DET men CMP-B3P-plant-AP corn A3S-RN DET corn DET corn

'The men planted (corn).'

Similarly to other intransitives, antipassivized predicates can undergo -ik nominalization. However, the derived event nominals receive an unexpected interpretation: as shown in (22), the Set A marker corresponds to the internal argument instead of the external one.

Antipassive in nominals

a. N-Ø-inw-ajo' [n-Ø-in-kan-uj aninäq].

ICMP-B3S-A1S-want ICMP-B3S-A1S-search-TV quickly

'I want to quickly look for it.'

\footnotetext{
${ }^{4}$ Constituents headed by relational nouns, including $(i)$ chin, are akin to prepositional phrases (Patal Majzul et al. 2000, Ranero 2019). Hence, it should not be surprising that a DP complement of such a relational noun can control PRO; cases of obligatory control from within a PP are well attested in other languages, including English: John pleaded [with Mary ] [PRO $_{i}$ to forgive him] (Farkas 1988, Sag \& Pollard 1991, Runner 2006, i.a.).

5 The inventory of antipassive constructions used in particular dialects of Kaqchikel varies; see Heaton (2017) for an overview. In descriptive grammars two types of antipassive constructions are distinguished (Patal Majzul et al. 2000). The incorporating antipassive requires the internal argument to be either deleted or incorporated; it is uniformly marked $-V n$. The absolutive antipassive demotes the internal argument to an oblique phrase; its exponent is usually - $o$ for CVC lexical roots and - $V n$ for derived transitive predicates; note that the same two suffixes are used in Kaqchikel in agent focus constructions, including the dialect examined in the present paper. In the Patzún variety of Kaqchikel under discussion the two antipassives are conflated: the means to demote the internal argument is not restricted and the morphological exponent is always $-V n$.
} 

b. N-Ø-inw-ajo' ri nu-kan-un-ik aninäq.
ICMP-B3S-A1 S-want DET A1 S-search-AP-NMZ quickly
'I want someone to quickly look for me.'
Intended, not available: 'I want to quickly look for something.'

Such behavior is peculiar since, under the assumption that antipassive is an operation on argument structure, we expect that under nominalization the internal argument would be either demoted or removed completely, while the external argument would survive, similarly to how antipassivization proceeds in finite clauses. However, in Patzún Kaqchikel exactly the opposite happens: the external argument disappears and cannot be encoded via a Set A marker, while the internal argument is still present and Case-licensed, as it cannot be a bare NP or an oblique phrase.
a. $\quad$ Röj x-Ø-qa-chäp
(ri) ru-sik'i-n-ik ri wuj / *r-chin ri wuj / we CMP-B3S-A1P-begin DET A3S-read-AP-NMZ DET book A3S-RN DET book *wuj.
book
'We began to read the book.'
Literally: 'We initiated reading the book.'
b. *Röj x-Ø-qa-chäp (ri) qa-sik'i-n-ik.
we CMP-B3S-A1P-begin DET A1P-read-AP-NMZ
Intended: 'We began to read.'

The observed puzzle can be described as follows.

Antipassive Puzzle

Antipassive under nominalization behaves as passive promoting an internal argument, while in clausal antipassive constructions only the external argument survives.

5.2. Clausal antipassive Structure. To analyze antipassive in finite clauses, we follow Ranero (2019) and assume that antipassive in Kaqchikel is not a special type of Voice but a morphological realization of $v^{0}$ in the absence of (transitive) Voice. In essence, Ranero examines various argument structure mismatches under ellipsis and notices that the Antipassive/Active mismatch is allowed, despite the generally accepted restriction on Voice mismatch under ellipsis in the world's languages (Merchant 2013, Rudin 2019, i.a.). To account for this, Ranero proposes that syntactic parallelism under ellipsis is satisfied by featural non-distinctness and that antipassive constructions lack Voice altogether, hence they are compatible with all other types of clauses. The phenomenon is also observed in the Patzún variety of Kaqchikel considered in this paper; examples are given in (25), where the elided part is in " $<>$ ". The structure of clausal antipassive is schematized in (26).

Antipassive and ellipsis in PK

Ja ri xta Maria X- $\varnothing-k a m-s a-n \quad$ (r-chin ri chiköp). Aw-etama-n achike FOC DET CL Maria CMP-B3S-die-CAUS-AP A3S-RN DET animal A2s-know-VB what (chiköp) $<\mathrm{x}-\emptyset-\varnothing$-kam-sa-j $>$ ? animal CMP-B3S-A3S-die-CAUS-TV

'MARIA killed someone/the animal. Do you know who/what animal she killed?' 
In the case of clausal antipassive, the structurally higher external argument intervenes between $\mathrm{Infl}^{0}$, which assigns ABS, and the internal argument and gets Case-licensed first, leaving the object caseless. Thus, the internal argument cannot be a DP, but only a smaller (incorporated) NP or an oblique phrase.

5.3. Deriving Antipassive nominals. Going back to the antipassive under nominalization puzzle, under the assumption that in mixed nominals the argument position within the extended verbal projection is occupied by a lexical DP, we expect to attest the same behavior of antipassive as in a finite clause: the external argument should survive the derivation and the internal argument should be removed or demoted. This, however, is contrary to the facts (22).

The predicative control analysis, however, successfully accounts for the antipassive puzzle. The verbal part of an -ik nominal contains a PRO variable merged in the argument position; the variable is controlled by a higher possessor merged in Spec,nP via predicative control, which requires movement of PRO to the edge of the predicate phrase. Since in antipassive nominals the verbal extended projection is structurally smaller (vP), operator initially merged as an external argument in Spec,vP has no higher position to move to. We argue that because of this, predication cannot be established and the derivation crashes. An alternative strategy is to merge PRO as an internal argument for it to raise to Spec,vP, while the external argument is structurally absent and gets saturated on the semantic level (Reinhart 2002). Thus, the structural representation for the "exceptional" antipassive nominals is outlined in (27).

\section{(27) Predicative control in antipassive nominals}

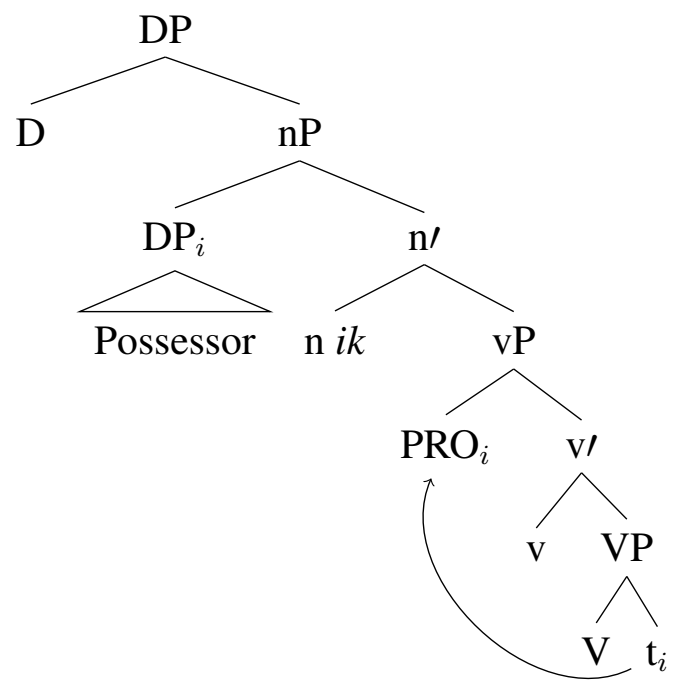

6. Conclusion. In this paper we focused on deverbal event nominalization in Kaqchikel, a Mayan language, and we developed a novel analysis for mixed nouns that consist of both verbal and nominal projections. First, we addressed the Restriction on Nominalization parameter put forward by Imanishi (2020), whereby in some Mayan languages, such as Kaqchikel, all nominalized verbs are presumed to lack an external argument projection. To formally account for the restriction, Imanishi stipulates that, in Kaqchikel, the nominalizing $n$ is equipped with a special feature which makes it able to non-locally select a verbal projection without an ex- 
ternal argument; note that the vP itself is still present. The present paper expanded the set of constructions considered by Imanishi and demonstrated that the restriction leaves some data unaccounted: in particular, unergative verbs preserve their arguments under nominalization. Thus, there is no empirical support for the proposed parameter and the selectional properties of $n$ should be restored to the commonly attested distinction between transitive and intransitive $v$, well-documented for Mayan languages (Coon et al. 2014).

Second, we focused on the question of whether the argument position in the verbal part of a mixed nominal is occupied by a referential DP or PRO, the two options evoking the wellknown raising/control dichotomy. Examining the Kaqchikel data, we argued that predicative control is essential to building a mixed nominal: the verbal extended projection is predicated of a possessor DP merged in Spec,nP, similarly to how control is established in complex sentences between the PRO subject of the embedded FinP and a matrix argument (Landau 2015). Additional support for this comes from the previously undescribed behavior of antipassive under nominalization that cannot be accounted for under a raising/ECM analysis. Thus, the paper contributes to the ongoing discussion of control in DPs and further enforces the parallelism between DP and CP (Coon 2010).

\section{References}

Alexiadou, Artemis. 2001. Functional structure in nominals: Nominalization and ergativity. Amsterdam: John Benjamins. https://doi.org/10.1075/la.42.

Baker, Mark. 2005. On gerunds and the theory of categories. Ms., Rutgers University.

Borsley, Robert D. \& Jaklin Kornfilt. 2000. Mixed extended projections. In Robert Borsley (ed.), The nature and function of syntactic categories, 101-131. New York: Academic Press. https://doi.org/10.1163/9781849500098 006.

Bresnan, Joan. 1997. Mixed categories as head sharing constructions. In Myriam Butt \& Tracy Holloway King (eds.), Proceedings of LFG97, 1-17. Stanford, CA: CSLI Publications.

Coon, Jessica. 2010. Rethinking split ergativity in Chol. International Journal of American Linguistics 76. 207-253. https://doi.org/10.1086/652266.

Coon, Jessica \& Elizabeth Carolan. 2017. Nominalizations and the structure of progressives in Chuj Mayan. Glossa: A Journal of General Linguistics 2. 22. https://doi.org/10.5334/gjg1.51.

Coon, Jessica, Pedro Mateo Pedro \& Omer Preminger. 2014. The role of case in A-bar extraction asymmetries: Evidence from Mayan. Linguistic Variation 14. 179-242. https://doi.org/10.1075/lv.14.2.01coo.

Farkas, Donka. 1988. On obligatory control.Linguistics and Philosophy 11. 27-58. https://doi.org/10.1007/BF00635756.

Grimshaw, Jane. 1990. Argument structure. Cambridge, MA: MIT Press.

Heaton, Raina. 2017. A typology of antipassives, with special reference to Mayan. Honolulu, HI: University of Hawaii at Manoa dissertation.

van Hout, Angeliek \& Thomas Roeper. 1998. Events and aspectual structure in derivational morphology. MIT Working Papers in Linguistics 32. 175-220.

Imanishi, Yusuke. 2020. Parameterizing split ergativity in Mayan. Natural Language \& Linguistic Theory 38. 151-200. https://doi.org/10.1007/s11049-018-09440-9.

Imanishi, Yusuke \& Pedro Mateo Pedro. 2013. Deriving nominals in Kaqchikel. In Michael Kenstowicz (ed.), Studies in Kaqchikel grammar, 51-66. Cambridge, MA: MIT Working Papers in Linguistics. 
Landau, Idan. 2015. A two-tiered theory of control. Cambridge, MA: MIT Press. https://doi.org/10.7551/mitpress/9780262028851.001.0001.

Levin, Theodore, Paulina Lyskawa \& Rodrigo Ranero. 2021. Optional agreement in Santiago Tz'utujil Mayan is syntactic. Zeitschrift für Sprachwissenschaft 39. 329-355. https://doi.org/10.1515/zfs-2020-2018.

Marantz, Alec. 1997. No escape from syntax: Don't try morphological analysis in the privacy of your own lexicon. Pennsylvania Working Papers in Linguistics 4.2. 201-225.

Merchant, Jason. 2013. Voice and ellipsis. Linguistic Inquiry 44. 77-108. https://doi.org/10.1162/LING a 00120.

Panagiotidis, Phoevos \& Kleanthes K. Grohmann. 2009. Mixed projections: Categorial switches and prolific domains. Linguistic Analysis 35. 141-161.

Patal Majzul, Filiberto, Lolmay Pedro García Matzar \& Carmelina Ixchel Espantzay Serech. 2000. Rujunamaxik Ri Kaqchikel Chi': Variación dialectal en Kaqchikel. Guatemala: Editorial Cholsamaj.

Ranero, Rodrigo. 2019. Voice mismatches in Kaqchikel sluicing: Consequences for syntactic parallelism. Ms., University of Maryland.

Reinhart, Tanya. 2002. The Theta System - an overview. Theoretical Linguistics 28. 229-290. https://doi.org/10.1515/thli.28.3.229.

Rudin, Deniz. 2019. Head-based syntactic identity in sluicing. Linguistic Inquiry 50. 253-283. https://doi.org/10.1162/ling a 00308.

Runner, Jeffrey T. 2006. Lingering challenges to the Raising-to-Object and Object Control constructions. Syntax 9. 193-213. https://doi.org/10.1111/j.1467-9612.2006.00088.x.

Sag, Ivan A. \& Carl Pollard. 1991. An integrated theory of complement control. Language 67. 63113. https://doi.org/10.2307/415539.

Williams, Edwin. 1980. Predication. Linguistic Inquiry 11. 203-238.

Yoon, James Hye Suk. 1996. Nominal gerund phrases in English as phrasal zero derivations. Linguistics 34. 329-56. https://doi.org/10.1515/ling.1996.34.2.329. 